\title{
Cheminer avec le conflit : compétences et stratégies pour l'action
}

Dekha Ibrahim Abdi, Simon Fisher, Jawed Ludin, Richard Smith, Steve et Sue Williams. Institut International pour l'Environnement et le

Développement (IIED), 2002

\section{Christian Mesnil}

\section{Q OpenEdition}

12 Journals

Édition électronique

URL : http://journals.openedition.org/communicationorganisation/3262

DOI : 10.4000/communicationorganisation.3262

ISSN : $1775-3546$

Éditeur

Presses universitaires de Bordeaux

Édition imprimée

Date de publication : 1 juin 2005

Pagination : 202-203

ISSN : $1168-5549$

\section{Référence électronique}

Christian Mesnil, «Cheminer avec le conflit : compétences et stratégies pour l'action », Communication et organisation [En ligne], 27 | 2005, mis en ligne le 07 juin 2012, consulté le 21 septembre 2020. URL : http://journals.openedition.org/communicationorganisation/3262 ; DOI : https://doi.org/10.4000/ communicationorganisation.3262

Ce document a été généré automatiquement le 21 septembre 2020.

(c) Presses universitaires de Bordeaux 


\section{Cheminer avec le conflit : compétences et stratégies pour l'action}

Dekha Ibrahim Abdi, Simon Fisher, Jawed Ludin, Richard Smith, Steve et Sue Williams. Institut International pour l'Environnement et le

Développement (IIED) ${ }^{1}, 2002$

\section{Christian Mesnil}

1 Rendre compte d'un tel ouvrage dans notre revue est inhabituel. Le livre constitue non une recherche fondamentale mais une sorte de recherche appliquée collective synthétisée a posteriori par six auteurs britanniques. Simon Fisher a été directeur de Responding to conflict depuis 1991. Jawed Ludin est l'Administrateur du Projet pour l'Afghanistan au Conseil Britannique pour les Réfugiés à Londres. Sue Williams a été entre autres Directrice de la cellule politique et évaluation d'INCORE (Initiative pour la Résolution des Conflits et l'Ethnicité) à l'Université d'Ulster/Université des Nations Unies. Steve Williams est un consultant qui a travaillé sur l'Irlande du Nord et de nombreux autres pays. Dekha Ibrahim Abdi est une médiatrice chevronnée dans les conflits communautaires notamment au Kenya et dans toute l'Afrique. Richard Smith enfin est membre de la coalition pour la paix en Afrique. Il intervient dans de nombreux processus de réconciliation et de reconstruction.

2 Cet ouvrage collectif présente comme seconde caractéristique de s'appuyer sur l'expérience de quelques trois cents praticiens qui sont intervenus depuis une quinzaine d'années à travers le monde pour tenter de désamorcer des conflits latents ou de permettre, qu'une communication et des projets soient à nouveau envisageables entre d'anciens belligérants. Ils ont tous travaillé à un moment ou à un autre dans le sillage de Responding to conflict, organisme international à but non lucratif dont le siège est à Birmingham au Royaume Uni. Cette organisation offre un appui à de nombreux partenaires à travers le monde aussi bien à la base, dans des villages ou des quartiers urbains, qu'au niveau gouvernemental ou international. Les situations de confrontation et de crise sont légion sur la planète et les processus à mettre en œuvre 
doivent sans cesse s'adapter à des contextes particuliers plus ou moins dramatiques (cf. Rwanda).

3 «Cheminer avec le conflit» propose quatre étapes: analyse, stratégie, action et apprentissage. Chaque étape pose un certain nombre de repères conceptuels avant de suggérer des outils méthodologiques variés pour réfléchir et intervenir de façon adaptée. Des tableaux et schémas nombreux, une mise en page (encarts, citations) et une typographie didactiques, une bibliographie (y compris vidéos et sites internet) et un index précis facilitent l'appropriation par le lecteur des contenus qui le motivent le plus.

4 En France, le politiquement correct, les consensus mous, les stratégies d'évitement, les conflits larvés sont souvent préférés à des conflits ouverts, violents et destructeurs. Les stratégies pour préserver le pouvoir, les parts de marché, le savoir technologique, pour gérer les crises ou contourner les obstacles font l'objet de conceptualisations sans cesse actualisées. Par ailleurs la gestion des ressources humaines s'intéresse avec les services juridiques, sociaux ou psychologiques aux victimes et aux perdants. Mais la prise en compte frontale d'une situation conflictuelle pour tenter de la dépasser objectivement avec les protagonistes paraît sinon peu fréquente du moins constituer plus rarement un objet d'observation et de conceptualisation. L'approche proposée ici est très dépaysante car elle se veut à la fois synthétique et détaillée, pragmatique et théorique avec une dimension interculturelle. Elle vise non à effacer ou à juger, non à privilégier la victime ou bannir l'émotion mais à permette l'émergence d'une parole qui, à son tour, réenclenchera des projets et permettra pour tous une remise en route, d'où l'idée de cheminement proposée par le titre français. Cet ouvrage anglo-saxon repose finalement sur une problématique qui mériterait, me semble-t-il, d'être davantage étudiée dans le champ de la communication des organisations en France.

5 1. L'édition française est distribuée par Earthprint Ld Po box 119 Stevenage Herts S G 17 T P Royaume Uni (copyright Responding to Conflict / IIED 2002). 